\title{
Predictive abilities of different statistical models for analysis of survival data in dairy cattle
}

\author{
M. Holtsmark, ${ }^{*} \dagger^{1}$ B. Heringstad, ${ }^{*} \dagger$ and J. Ødegård ${ }^{*} \ddagger$ \\ *Department of Animal and Aquacultural Sciences, Norwegian University of Life Sciences, PO Box 5003, N-1432 Ås, Norway \\ †Geno Breeding and A.I. Association, PO Box 5003, N-1432 Ås, Norway \\ ¥Nofima, PO Box 5010, N-1432 Ås, Norway
}

\section{ABSTRACT}

The objective of this study was to compare alternative trait definitions and statistical models for genetic evaluation of survival in dairy cattle. Data from the first 5 lactations of 808,750 first-crop daughters of 3,064 Norwegian Red sires were analyzed. Seven sire models were used for genetic analyses: linear and threshold cross-sectional models for binary survival scores from first lactation; a linear multi-trait model for survival scores from the first 3 lactations; linear and threshold repeatability models for survival scores from the first 5 lactations; a Weibull frailty model for herd life in first lactation; and a Weibull frailty model for herd life in the first 5 lactations. The models were compared to assess predictive ability of sire estimated breeding values with respect to average survival $365 \mathrm{~d}$ after first calving for second-crop daughters (not included in calculation of predicted transmitting abilities) of 375 elite sires. Generally, the linear multi-trait model analyzing survival in the first 3 lactations as correlated traits gave more-accurate predicted sire breeding values compared with both linear and Weibull frailty models using data from first lactation only, even when the latter models were extended to include data up to the sixth lactation. The Weibull frailty models did not improve predictive ability of sire estimated breeding values over what was obtained using a simple cross-sectional linear model for binary survival in first lactation.

Key words: predictive ability, model comparison, survival

\section{INTRODUCTION}

Longevity traits are included in the routine breeding value evaluations in many countries, and proportional hazard models or multi-trait models are most commonly used (Interbull, 2009a). Generally, a long herd life reduces replacement costs and increases the

Received February 16, 2009.

Accepted August 11, 2009.

${ }^{1}$ Corresponding author: marte.holtsmark@umb.no number of mature lactations. Culling can be divided into voluntary (e.g., due to low production) and involuntary culling (e.g., due to health or fertility problems). Reduced rate of involuntary culling enables farmers to increase the rate of voluntary culling such that profit is maximized, and thus may not necessarily lead to longer average herd life (van Arendonk, 1985). The economic value of reducing involuntary culling is highest in the first lactations.

True longevity has the disadvantage that it cannot be recorded before a cow is culled. This leads to rightcensoring of data when breeding values are predicted while animals still are alive. In analysis of longevity traits the proportional hazards model (Ducrocq and Sölkner, 2000) has the advantage that it is able to utilize all data, including censored records. An alternative approach is to score survival as a binary trait; that is, survived or not up to a specific time, age, or event, and analyze the binary data with linear or threshold models. Use of binary survival implies that only the animals having the opportunity to survive the entire specified period can be used in genetic analysis, and records from the most recent animals will thus be excluded. Proportional hazards models analyzing time until death and treating surviving animals as censored may therefore be a better alternative. However, the most commonly used software for proportional hazards models is still restricted to univariate analyses (Ducrocq and Sölkner, 2000). In comparison, some software packages for linear or threshold models can handle multivariate genetic analysis (e.g., the DMU package; Madsen and Jensen, 2008), which enables use of information from correlated traits. Furthermore, the problems of censored lifetime data in linear or threshold models can, to some extent, be circumvented by splitting the lifespan in several intervals and define survival within each period as a binary trait (survival scores). Hence, each animal will have several records depending on the recorded lifespan, and information from younger animals can therefore be used to a greater extent. The latter method will also take into account time until death, because older animals will have several periods when they are scored 
as survived before being scored as dead in the last period.

The objective was to compare alternative trait definitions and statistical models for genetic evaluation of survival in dairy cattle. Proportional hazards models (Weibull frailty) were compared with univariate linear and threshold models, using different trait definitions of survival. The models' ability to predict survival (culled or survived) in first lactation of future (second-crop) daughters of the same sires (i.e., predictive ability of sire EBV) was used for model comparison. Survival in different lactations has moderate to high genetic correlations (Jairath and Dekkers, 1994; Boettcher et al., 1999; Sewalem et al., 2007), and the aim of this study was to examine whether use of information up to the sixth lactation improves the predictive ability of the sire EBV using Weibull frailty, linear and threshold repeatability survival score models, and linear multi-trait survival score models.

\section{MATERIALS AND METHODS}

\section{Data}

Data were obtained from the Norwegian Dairy Herd Recording System. The first data set (data set 1) contained information on lactation number and calving and culling dates for the first 5 lactations of 808,750 first-crop daughters (birth-year $\leq 6 \mathrm{yr}$ after the birth of the sire) of 3,064 Norwegian Red sires. Data set 1 was used to predict sire breeding values for daughter survival. The second data set (data set 2) had records on calving and culling dates for the first lactation of $1,130,255$ second-crop daughters (birth year $>6$ yr after the birth of the sire) of 375 elite sires (sires also included in data set 1). Each elite sire had at least 1,000 second-crop daughters. Data set 2 was used for evaluation of predictive ability of the predicted sire breeding values. For both data sets, first calving had to be between 1980 and 2005, at 20 to 40 mo of age. Daughters with first calving before year 2000 were required to have a recorded date of culling, whereas the remaining cows with a missing date of culling were assumed to be alive on February 20, 2006 (truncation point). This implies that all cows had the opportunity to finish at least one lactation. In data set 1 , cows with calving intervals shorter than 10 mo or longer than 24 mo, and cows that were culled more than 24 mo after last recorded calving were excluded. Cows having missing calving records before the last calving or double calving records for specific calvings were also deleted. Number of records and percentage of cows surviving per lactation are shown in Table 1. Although $68 \%$ of
Table 1. Number of cows for each lactation and percentage of cows surviving the lactation

\begin{tabular}{lcc}
\hline Lactation & Cows starting lactation, $\mathrm{n}$ & Surviving cows, $\%$ \\
\hline 1 & 800,331 & 68.0 \\
2 & 543,898 & 42.7 \\
3 & 341,752 & 23.7 \\
4 & 190,062 & 11.7 \\
5 & 93,927 & 5.6 \\
\hline
\end{tabular}

the cows survived the first lactation, only $5.6 \%$ of the cows survived until the end of the fifth lactation.

In data set 1 , three longevity traits were defined: 1 ) herd life in the first 5 lactations (survL1-5), calculated as the number of days from first calving to either culling from the herd or censoring (record of a sixth calving or end of recording period); 2) herd life in first lactation (survL1), calculated as number of days from first calving to either culling or censoring (record of a second calving or end of recording period); and 3) survival scores for lactation 1 to $5\left(\mathbf{S S}_{\mathrm{k}}, k=1-5\right)$, with $\mathrm{SS}_{\mathrm{k}}$ scored as 1 if the cow had a calving $k+1$, zero if the cow was culled in lactation $k$, and missing if the cow was culled before the lactation or if recording period ended during lactation $k$. Animals culled on the same day as they calved were given a herd life of 1 , and lactation survival scores were set as missing for lactations in progress at the end of the recording period. Survival scores were obtained for 799,814 first-lactation cows, which is slightly lower than the number of cows with herd life records (Table 1). Among cows with a firstlactation survival score, 536,452 survived to the second lactation, 329,381 to the third, 183,109 to the fourth, 90,262 to the fifth and 41,096 to the sixth lactation.

In data set 2, survival $365 \mathrm{~d}$ after first calving was scored as 0 if the cow was culled before $365 \mathrm{~d}$ after first calving, and 1 otherwise. In total, $26 \%$ of the secondcrop daughters were scored as culled.

The sire pedigree file had records of the 3,064 sires with daughters, together with their sire and maternal grand-sires traced back as far as possible, including a total of 3,756 sires.

\section{Weibull Frailty Model, Lactations 1 to 5}

To optimize the Weibull frailty model, lactations 1 to 5 (WFM1-5), Kaplan-Meier curves were plotted for each of the first 5 lactations. After evaluating the curves it was decided to analyze herd life up to the sixth lactation (survL1-5) using the following sire model:

$$
h_{i j k l m n}(t)=h_{0}(t) \exp \left\{\begin{array}{l}
A F C_{j}+Y M_{k}+\operatorname{LACTSTAGE}\left(t_{1}\right) \\
+h y_{i}\left(t_{2}\right)+\operatorname{sire}_{m}
\end{array}\right\},[1]
$$


where $h_{i j k l m n}(t)$ is the hazard function for a daughter $n$ of a given sire $m$, with recorded herd life $t$ (days from first calving to culling or censoring); $h_{0}(t)$ is the Weibull baseline hazard function, with scale parameter $\tau$ and shape parameter $\rho ; A F C_{j}$ is a fixed effect of age $j$ at first calving (21 classes); $Y M_{k}$ is a fixed effect of year by month $k$ of first calving (316 classes); LACTSTAGE $\left(t_{1}\right)$ is a time-dependent fixed effect of stage of lactation, assumed to be piecewise constant, changing at $t_{1}=$ 0,14 , and $148 \mathrm{~d}$ after calving within each lactation (15 classes); $h y_{i}$ is a time-dependent random effect of herd-year $i$ of calving, assumed to follow a log-gamma distribution with parameter $\gamma$ and assumed to be piecewise constant, changing at $t_{2}=$ January 1 each year; and sire $_{m}$ is a random effect of sire $m$.

\section{Weibull Frailty Model, Lactation 1}

The Weibull frailty model, lactation 1 (WFM1) used was identical to the model above but restricted to first lactation only. All cows surviving first lactation were assumed to have right-censored herd life. Consequently, only 3 lactation-stage effects were fitted [3 classes for LACTSTAGE $\left(\mathrm{t}_{1}\right)$ ], whereas for the remaining fixed effects the number of classes were the same as for WFM1-5.

\section{Linear Repeatability Model and Threshold Repeatability Model, Lactations 1 to 5}

Binary survival scores for the first 5 lactations $\left(\mathrm{SS}_{1}\right.$ - $\mathrm{SS}_{5}$ ) were analyzed with the following linear repeatability sire model (LRM):

$$
Y_{i j k l m n}=A F C_{i}+Y M_{j}+L A C T_{k}+h y_{l}+\text { sire }_{m}+e_{i j k l m n},
$$

where $Y_{i j k l m n}$ is the survival score of a daughter $n$ of sire $m$, in lactation $k ; A F C_{i}$ is the fixed effect of age $i$ at first calving (21 classes); $Y M_{j}$ is the fixed effect of year by month $j$ of first calving (316 classes); $L A C T_{k}$ is the fixed effect of lactation number $k ; h y_{l}$ is the random effect of herd-year $l$ of calving for lactation $k$; sire $_{m}$ is the random effect of sire $m$; and $e_{i j k l m n}$ is the residual effect. In addition, using the same model, SS1-SS5 were analyzed with a threshold repeatability model (TRM; assuming a probit link function).

\section{Linear Cross-Sectional Model and Threshold Cross-Sectional Model, Lactation 1}

Survival score for first lactation $\left(\mathrm{SS}_{1}\right)$ was analyzed with both a linear (linear cross-sectional, LCM) and a threshold cross-sectional (TCM; probit link) model using a model identical to model [2], but without the effect of lactation number.

\section{Linear Multi-Trait Model, Lactations 1 to 3}

To limit the number of parameters multi-trait analysis of survival score was done only for the first 3 lactations (linear multitrait model; LMM). The data were analyzed using a linear sire model:

$$
\mathbf{Y}=\mathbf{X} \boldsymbol{\beta}+\mathbf{Z}_{1} \mathbf{h y}+\mathbf{Z}_{2} \mathbf{S}+\mathbf{e},
$$

where $\mathbf{Y}$ is a vector of survival scores for the first 3 lactations; $\boldsymbol{\beta}=\left[\boldsymbol{\beta}_{1}{ }^{\mathrm{t}} \boldsymbol{\beta}_{2}{ }^{\mathrm{t}} \boldsymbol{\beta}_{3}{ }^{\mathrm{t}}\right]$ is a vector of lactation-specific fixed effects, where $\boldsymbol{\beta}_{\mathrm{k}}$ includes the effects of age at first calving (21 classes), and year by month of first calving (316, 316, and 308 classes for first, second and third lactations, respectively) in lactation $k$; hy $=\left[\mathbf{h y}_{1}{ }^{\mathrm{t}} \mathbf{h} \mathbf{y}_{2}{ }^{\mathrm{t}}\right.$ $\left.\mathbf{h y}_{3}{ }^{\mathrm{t}}\right]$ is a vector of random herd-year effects, where $\mathbf{h} \mathbf{y}_{\mathrm{k}}$ is the random herd-year effect of calving in lactation $k$; $\mathbf{s}=\left[\mathbf{s}_{1}{ }^{\mathrm{t}} \mathbf{S}_{2}{ }^{\mathrm{t}} \mathbf{S}_{3}{ }^{\mathrm{t}}\right]$ is a vector of random sire effects, where $\mathbf{s}_{\mathrm{k}}$ is the random sire effect in lactation $k$; $\mathbf{e}$ is a vector of the random residuals; and $\mathbf{X}, \mathbf{Z}_{1}$, and $\mathbf{Z}_{2}$ are the corresponding incidence matrices. Furthermore, hy $\sim \mathrm{N}(0$, $\mathbf{H} \otimes \mathbf{I}), \mathbf{s} \sim \mathrm{N}(0, \mathbf{G} \otimes \mathbf{A})$, and $\mathbf{e} \sim \mathrm{N}(0, \mathbf{R} \otimes \mathbf{I})$, where

$$
\begin{gathered}
\mathbf{H}=\left[\begin{array}{ccc}
\sigma_{h y 1}^{2} & \sigma_{h y 1, h y 2} & \sigma_{h y 1, h y 3} \\
\sigma_{h y 2, h y 1} & \sigma_{h y 2}^{2} & \sigma_{h y 2, h y 3} \\
\sigma_{h y 3, h y 1} & \sigma_{h y 3, h y 2} & \sigma_{h y 3}^{2}
\end{array}\right], \\
\mathbf{G}=\left[\begin{array}{ccc}
\sigma_{s 1}^{2} & \sigma_{s 1, s 2} & \sigma_{s 1, s 3} \\
\sigma_{s 2, s 1} & \sigma_{s 2}^{2} & \sigma_{s 2, s 3} \\
\sigma_{s 3, s 1} & \sigma_{s 3, s 2} & \sigma_{s 3}^{2}
\end{array}\right],
\end{gathered}
$$

and

$$
\mathbf{R}=\left[\begin{array}{ccc}
\sigma_{e 1}^{2} & 0 & 0 \\
0 & \sigma_{e 2}^{2} & 0 \\
0 & 0 & \sigma_{e 3}^{2}
\end{array}\right]
$$

where $\sigma_{h y i}^{2}, \sigma_{s i}^{2}, \sigma_{e i}^{2}$ are the herd-year, sire, and residual variances for lactation $i$, respectively, $\sigma_{h y i, h y}$ and $\sigma_{s i, s j}$ are the herd-year and sire covariances between lactation $i$ and $j$, and $\mathbf{A}$ is the additive genetic relationship matrix of the 3,756 sires. The $\mathbf{R}$ matrix was restricted to be diagonal because of the sequential structure of survival data (i.e., only survivors will have records in next lactation). 
The proportional hazards models (WFM1-5 and WFM1) were run with the Survival Kit software (Ducrocq and Sölkner, 2000), whereas the DMU package (using AI-REML; Madsen and Jensen, 2008) was used for the other models (LCM, LRM, LMM, TCM, and TRM).

For the linear models, within-herd heritabilities were calculated as

$$
h^{2}=\frac{4 \sigma_{s}^{2}}{\sigma_{s}^{2}+\sigma_{e}^{2}},
$$

where $\sigma_{s}^{2}$ and $\sigma_{e}^{2}$ are the sire and residual variances, respectively. Standard errors of within-herd heritabilities were calculated as

$s e\left(h^{2}\right)=\operatorname{sqrt}\left[\left|\frac{\partial h^{2}}{\partial \sigma_{s}^{2}}\right|^{2} \sigma_{\sigma_{a}^{2}}^{2}+\left(\frac{\partial h^{2}}{\partial \sigma_{e}^{2}}\right)^{2} \sigma_{\sigma_{e}^{2}}^{2}+2\left(\frac{\partial h^{2}}{\partial \sigma_{s}^{2}}\right)\left(\frac{\partial h^{2}}{\partial \sigma_{e}^{2}}\right) \sigma_{\sigma_{a}^{2} \sigma_{e}^{2}}\right]$,

where

$$
\left(\frac{\partial h^{2}}{\partial \sigma_{s}^{2}}\right)=\frac{4 \sigma_{e}^{2}}{\left(\sigma_{s}^{2}+\sigma_{e}^{2}\right)^{2}}
$$

and

$$
\left(\frac{\partial h^{2}}{\partial \sigma_{e}^{2}}\right)=-\frac{-4 \sigma_{s}^{2}}{\left(\sigma_{s}^{2}+\sigma_{e}^{2}\right)^{2}}
$$

(Jensen and Madsen, 2005). For the threshold models, within-herd heritability on the underlying liability scale was estimated, assuming $\sigma_{e}^{2}=1$, and for the proportional hazards models, the equivalent within-herd heritability was calculated as

$$
h_{e q u}^{2}=\frac{4 \sigma_{s}^{2}}{\sigma_{s}^{2}+(1 / p)},
$$

where $p$ is the proportion of progeny not longer alive at a given time $t$ (Yazdi et al., 2002). The term "equivalent" refers here to the fact that the proof of sire $i$ with $n$ daughters would get the same reliability as if it were evaluated on a linear trait with the same heritability.

\section{Model Comparison}

The models were compared with respect to the ability of the sire evaluations to predict average survival $365 \mathrm{~d}$ after first calving for the second-crop daughters of the 375 elite sires. Predictive ability was examined through Pearson correlations between the average survival of the second-crop daughters and the predicted sire EBV, which is expected to be proportional to accuracy of selection (Ødegård et al., 2003). Equality of Pearson correlation coefficients of the different models were tested using the pair-wise $t$-test of Williams' modification of Hotelling's test (Dunn and Clark, 1971):

$$
t=\frac{\left(r_{s i}-r_{s j}\right)-\left[(n-3)\left(1+r_{i j}\right) / 2 D_{3}\right]^{1 / 2}}{\sqrt{1+\frac{(n-3)\left(r_{s i}+r_{s j}\right)^{2}\left(1-r_{i j}\right)^{3}}{8(n-1) D_{3}}}},
$$

where $r_{s i}$ and $r_{s j}$ are the Pearson correlations between the average survival of the second-crop daughters and EBV predicted by model $i$ and $j$, respectively; $r_{i j}$ is the Pearson correlation between EBV predicted by model $i$ and $j ; n$ is the number of sires with second-crop daughters (375); and $D_{3}$ is the determinant of the sample correlation matrix.

Predictive ability was also examined using the Pearson chi-square statistics $\left(\chi^{2}\right)$ based on logistic regression of the survival rate of second crop daughters on the predicted sire breeding values for each model. The Pearson $\chi^{2}$ for model $m$ can be written as

$$
\chi_{m}^{2}=\sum_{s=1}^{375}\left[n_{s}\left(\frac{\left(p_{s}-\hat{p}_{m s}\right)^{2}}{\hat{p}_{m s}}+\frac{\left(\hat{p}_{m s}-p_{s}\right)^{2}}{\left(1-\hat{p}_{m s}\right)}\right)\right] \text {, }
$$

where $n_{s}$ is the number of second-crop daughters of sire $s, p_{s}$ is the observed fraction of second-crop daughters of sire $s$ surviving $365 \mathrm{~d}$ after first calving, and $\hat{p}_{m s}$ is the corresponding expected fraction of surviving daughters based on logistic regression on predicted sire breeding values from model $m$. A low $\chi^{2}$ value indicates accurate predictions, and the model with the lowest value was considered to have the best accuracy of selection with respect to $365 \mathrm{~d}$ survival in future daughters.

\section{RESULTS}

Survival functions $\{\ln [-\ln (\mathrm{S})]\}$ for the first 5 lactations (survL1-5) are shown in Figure 1. The curves were not entirely parallel, which suggests that the analysis could benefit from stratification; for example, by lactation stage. However, to limit the number of parameters to be estimated, we chose to algebraically integrate out the random herd-year effect, which, because of software limitations, could not be combined with stratification (Ducrocq and Sölkner, 2000). Hence, a model with a 
Table 2. Estimated sire variance, parameter of the log-gamma distribution of herd-year effects $(\gamma)$, parameter of the Weibull distribution $(\rho)$, and equivalent within-herd heritability $\left(h_{\text {equ }}^{2}\right)$ for culling hazard up to lactation five (survL1-5), and culling hazard in first lactation (survL1) analyzed separately with Weibull frailty models (WFM1-5 and WFM1, respectively)

\begin{tabular}{lcrll}
\hline Model & Sire variance & $\gamma$ & $\rho$ & $h_{\text {equ }}^{2}$ \\
\hline WFM1-5 & 0.0107 & 13.35 & 1.10 & 0.04 \\
WFM1 & 0.0120 & 6.12 & 1.02 & 0.02 \\
\hline
\end{tabular}

single baseline hazard function combined with timedependent lactation-stage and herd-year effects was chosen for further analyses. As indicated in Figure 1, the curves were not entirely straight; therefore, a fixed effect of lactation stage was included in the model, changing on 14 and 148 DIM (corresponding with 2.6 and 5.0 on the logarithmic scale) within each lactation.

Estimated parameters from the survival analysis of herd life in first lactation (survL1), and herd life up to the sixth lactation (survL1-5) are shown in Table 2. For survL1 and survL1-5, 68 and $9 \%$ of the records were censored, respectively. Average failure time was at $203 \mathrm{~d}$ after first calving for survL1 and at $694 \mathrm{~d}$ for survL1-5. The average censoring time was at 385 and 1,547 d after first calving, respectively. Estimated within-herd heritabilities for survL1 and survL1-5 were 0.02 and 0.04 , respectively.

Variance components and within-herd heritabilities for survival from LCM and TCM (first lactation), and LRM and TRM (first to fifth lactation) are shown in
Table 3, and (co)variance components and within-herd heritability estimates from LMM (first, second, and third lactations) are given in Table 4 . When using linear models, the estimated within-herd heritabilities for survival in the first lactation (LCM and LMM), and for survival in the first 5 lactations (LRM) were all 0.02 $(\mathrm{SE}=0.001)$, whereas survival in the second and third lactations (LMM) had an estimated within-herd heritability of 0.03 ( $\mathrm{SE}=0.002)$. As expected for threshold models, the estimated within-herd heritability for survival in the first lactation (TCM) and survival in the first 5 lactations (TRM) on the underlying scale were doubled compared with the linear model estimates. As shown in Table 4, the genetic correlations between survival in the first and second lactations, and first and third lactations were $0.85(\mathrm{SE}=0.022)$ and $0.66(\mathrm{SE}$ $=0.034)$, respectively, whereas the genetic correlation between survival in the second and third lactations was $0.93(\mathrm{SE}=0.022)$. This may indicate that survival in first lactation is a somewhat different trait compared with survival in later lactations. Correlations between herd-year effects of first and second, first and third, and second and third lactations were $0.57,0.36$, and 0.75 , respectively, which indicates that the effect of a given environment changes over lactations, and is most pronounced between the first and later lactations.

Based on the $\chi^{2}$ statistics (Table 5), the LMM using data from the first 3 lactations had the best predictive ability of survival $365 \mathrm{~d}$ after first calving for secondcrop daughters, followed by TCM, LCM, TRM, LRM, WFM1, and WFM1-5. The Pearson correlations between the predicted sire EBV and the average survival

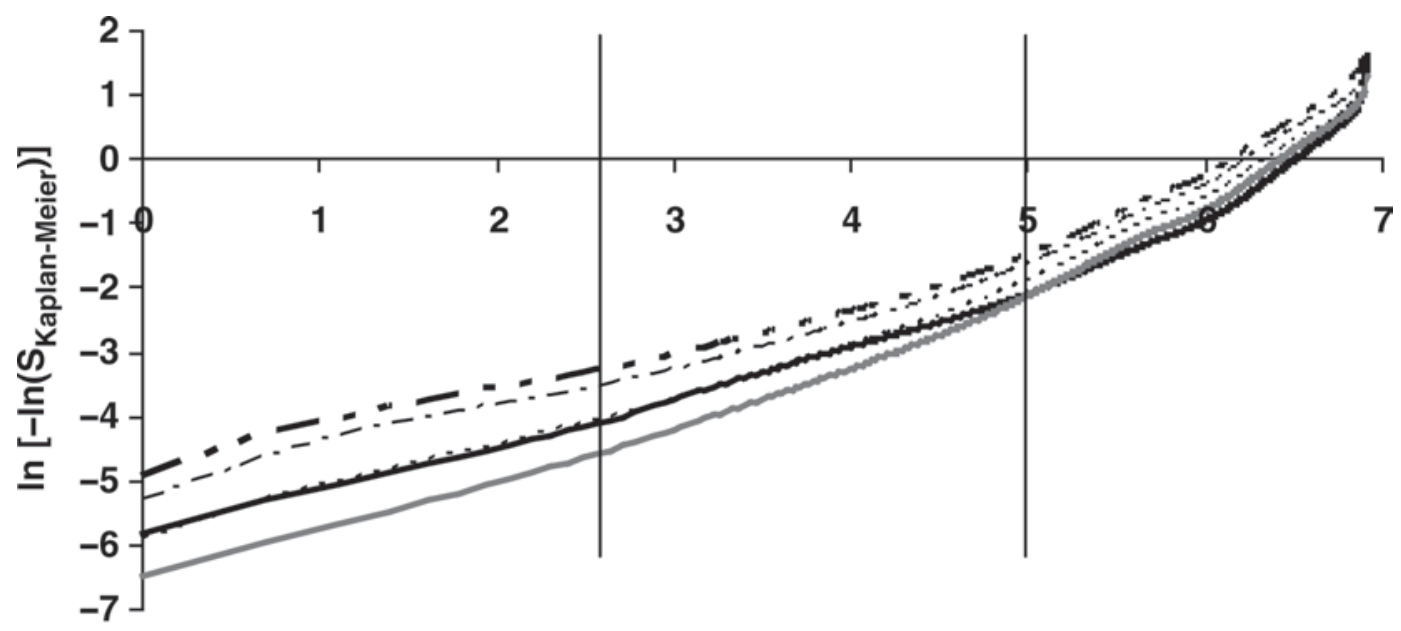

$\ln (\mathrm{t})$

Lact. 1

Lact. 2 -..... Lact. 3 - - - - Lact. 4 - - - Lact. 5

Figure 1. Plot of survivor function $\ln [-\ln (\mathrm{S})]$ on logarithm of days from calving (t) in lactation (Lact.) 1 to 5 . Vertical lines show where the boundaries for the stage of lactation effects were set in the analysis $[\ln (\mathrm{t})=2.64$, and 5.00]. 
Table 3. Estimated variance components and within-herd heritabilities $\left(h^{2}\right.$, SE) for survival in the first 5 lactations from a linear repeatability model (LRM), and a threshold repeatability model (TRM), and for survival in first lactation from a linear cross-sectional model (LCM) and a threshold cross-sectional model $(\mathrm{TCM})$

\begin{tabular}{lcccc}
\hline & \multicolumn{3}{c}{ Variance component estimates $^{1}$} \\
\cline { 2 - 3 } Model & Sire & Herd-year & Residual & $h^{2}$ \\
\hline LRM & 0.001 & 0.006 & 0.222 & $0.02(0.001)$ \\
LCM & 0.001 & 0.012 & 0.204 & $0.02(0.001)$ \\
TRM & 0.009 & 0.051 & 0.966 & $0.04(0.001)$ \\
TCM & 0.009 & 0.110 & 0.919 & $0.04(0.002)$ \\
\hline
\end{tabular}

${ }^{1}$ Standard errors of variance components ranged from $4.6 \times 10^{-5}$ to $2.1 \times 10^{-3}$, with the smallest SE being obtained for the smallest estimates of variance components and vice versa.

in second-crop daughter groups (Table 5) also indicated that LMM had the best predictive ability, followed by the repeatability models (LRM and TRM), the crosssectional models (LCM and TCM) and WFM1 and WFM1-5. The difference between the correlation of LMM and the correlations of other models were clearly significant $(P \leq 0.01)$, except for $\operatorname{LRM}(P=0.06)$ and TRM $(P=0.07$; Table 6$)$. Based on these correlations, the best model (LMM) is expected to have $14 \%$ higher accuracy of selection compared with the worst model (WFM1-5; Table 5).

\section{DISCUSSION}

The estimated within-herd heritability of 0.03 for survL1 and survL1-5 using WFM were slightly lower than the equivalent within-herd heritability calculated from the reported sire variances and censoring percentages by Caraviello et al. (2004; 0.05), who analyzed survival in the first 5 lactations in Jersey cows with a proportional hazards model. The estimated within-herd heritabilities for survival from the linear models $(0.02$ to 0.03$)$ corresponded well with the estimate of HaileMariam et al. (2003; 0.02) for survival in the first lactation from a linear-multi-trait model analyzed with fertility and production traits. Jairath and Dekkers (1994) found somewhat higher estimates of 0.12 and 0.04 for survival of the first and second lactations, respectively, using a linear multi-trait sire model. However, heritability estimates of binary traits from linear models are frequency dependent, and cannot be compared directly. The heritabilities estimated with the threshold models

Table 4. Estimated variance components (on the diagonal), covariances (below the diagonal), correlations (above the diagonal), and within-herd heritabilities, with standard errors in parentheses, for survival in the first 3 lactations (L1-3) from the linear multi-trait model analysis

\begin{tabular}{|c|c|c|c|c|}
\hline \multirow[b]{2}{*}{ Variance component } & \multirow[b]{2}{*}{ Lactation } & \multicolumn{3}{|c|}{ Lactation } \\
\hline & & 1 & 2 & 3 \\
\hline \multirow[t]{3}{*}{ Sire } & 1 & $\begin{array}{l}0.001 \\
\left(0.54 \times 10^{-4}\right)\end{array}$ & $\begin{array}{l}0.85 \\
(0.022)\end{array}$ & $\begin{array}{l}0.66 \\
(0.034)\end{array}$ \\
\hline & 2 & $\begin{array}{l}0.001 \\
\left(0.51 \times 10^{-4}\right)\end{array}$ & $\begin{array}{l}0.002 \\
\left(0.78 \times 10^{-4}\right)\end{array}$ & $\begin{array}{c}0.93 \\
(0.022)\end{array}$ \\
\hline & 3 & $\begin{array}{l}0.001 \\
\left(0.56 \times 10^{-4}\right)\end{array}$ & $\begin{array}{l}0.001 \\
\left(0.71 \times 10^{-4}\right)\end{array}$ & $\begin{array}{l}0.002 \\
\left(0.11 \times 10^{-3}\right)\end{array}$ \\
\hline \multirow[t]{3}{*}{ Herd-year } & 1 & $\begin{array}{l}0.012 \\
\left(0.25 \times 10^{-3}\right)\end{array}$ & $\begin{array}{l}0.57 \\
(0.026)\end{array}$ & $\begin{array}{l}0.36 \\
(0.030)\end{array}$ \\
\hline & 2 & $\begin{array}{l}0.006 \\
\left(0.22 \times 10^{-3}\right)\end{array}$ & $\begin{array}{l}0.008 \\
\left(0.37 \times 10^{-3}\right)\end{array}$ & $\begin{array}{c}0.78 \\
(0.048)\end{array}$ \\
\hline & 3 & $\begin{array}{l}0.004 \\
\left(0.29 \times 10^{-3}\right)\end{array}$ & $\begin{array}{l}0.007 \\
\left(0.34 \times 10^{-3}\right)\end{array}$ & $\begin{array}{l}0.009 \\
\left(0.60 \times 10^{-3}\right)\end{array}$ \\
\hline \multirow[t]{3}{*}{ Residual } & 1 & $\begin{array}{l}0.204 \\
\left(0.39 \times 10^{-3}\right)\end{array}$ & & \\
\hline & 2 & 0 & $\begin{array}{l}0.220 \\
\left(0.55 \times 10^{-3}\right)\end{array}$ & \\
\hline & 3 & 0 & 0 & $\begin{array}{l}0.225 \\
\left(0.80 \times 10^{-3}\right)\end{array}$ \\
\hline$h^{2}$ & & $\begin{array}{l}0.02 \\
(0.001)\end{array}$ & $\begin{array}{l}0.03 \\
(0.002)\end{array}$ & $\begin{array}{l}0.03 \\
(0.002)\end{array}$ \\
\hline
\end{tabular}


Table 5. Pearson $\chi^{2}$ statistics for prediction of survival 365-d after first calving in second-crop daughters from sire EBV based on first-crop daughters, Pearson correlations between survival rate of second-crop daughters and sire EBV, and Pearson correlations between sire EBV from the different models

\begin{tabular}{lcccccccc}
\hline & & \multicolumn{5}{c}{ Pearson correlations } \\
\cline { 3 - 8 } Model $^{1}$ & $\chi^{2}$ & LMM & LCM & LRM & TCM & TRM & WFM1 & Second-crop survival \\
\hline LMM & $3,896.57$ & & & & & 0.65 \\
LCM & $4,161.63$ & 0.94 & & & & 0.61 \\
LRM & $4,190.32$ & 0.94 & 0.80 & & & 0.62 \\
TCM & $4,152.17$ & 0.94 & 1.00 & 0.80 & & & 0.61 \\
TRM & $4,171.32$ & 0.94 & 0.80 & 1.00 & 0.80 & & 0.62 \\
WFM1 $^{2}$ & $4,268.47$ & 0.92 & 0.99 & 0.79 & 0.99 & 0.79 & 0.61 \\
WFM1-5 $^{n}$ & $4,525.14$ & 0.90 & 0.75 & 0.98 & 0.74 & 0.98 & 0.76 & 0.59 \\
\hline
\end{tabular}

${ }^{1} \mathrm{LMM}=$ linear multi-trait model; LCM $=$ linear cross-sectional model; LRM $=$ linear repeatability model; TCM $=$ threshold cross-sectional model; TRM $=$ threshold repeatability model; WFM1 = Weibull frailty models using first lactation only (WFM1) lactation; and WFM1-5 = Weibull frailty models using data up to fifth lactation.

${ }^{2}$ To obtain conformity with respect to the sign of the correlations, all correlations between WFM1 and WFM1-5, and the other traits have been multiplied by -1.0 , since EBV for WFM1 and WFM1-5 measures the risk of culling, whereas for the other traits the EBV measures survival.

in the current study were equal to the estimate from a multi-trait threshold model analysis of the same data set (0.04; Holtsmark et al., 2008).

Longevity traits are most commonly analyzed in a single-trait analysis, using sire, maternal grandsire, or sire-maternal grandsire survival models. However, repeatability animal models, random regression animal models, multitrait animal models, single-trait animal models, and multitrait sire models are also used (Interbull, 2009b). In this study, the sire EBV from threshold and linear models performed equally well, and better than those from Weibull frailty models, at least when predicting survival $365 \mathrm{~d}$ after first calving for secondcrop daughters. Caraviello et al. (2004) compared predictive abilities of sire EBV from Weibull frailty sire models and linear animal models for survival up to the second, third, fourth, and fifth lactations, and found that none of the models were superior, but the Weibull model tended to perform somewhat better. A simulation study by Jamrozik et al. (2008) indicated that the Weibull model was better at predicting functional survival (survival assumed independent of production), whereas linear random-regression models and linear multi-trait models were better at predicting overall survival (survival affected by health and fertility, as well as production). When examining the predicted sire EBV ability to predict survival up to a given point in time, it is the average general survival and not the functional survival of the daughters that is measured. Hence, according to Jamrozik et al. (2008), this would favor the linear models. In this study, the amount of censored data (i.e., not being used in the linear model analyses) was limited, implying that the WFM will not have a great advantage over the linear and threshold models. However, in progeny testing schemes, where most daughters have barely finished their first lactation at the time of the first genetic evaluation of the sire, use of WFM may increase the number of records that can be included in genetic evaluations. This may alter the accuracy of selection in favor of WFM relative to linear models.

In this study, predicted sire breeding values from the LMM performed best, whereas sire EBV obtained from the LCM and TCM performed similarly to those obtained from the LRM and TRM. Furthermore, sire EBV obtained from the WFM1 performed better than

Table 6. $P$-values from pair-wise $t$-tests for differences between absolute value of correlations of first-crop sire EBV from the different models and second-crop survival rate in first lactation ${ }^{1}$

\begin{tabular}{lccccc}
\hline & LMM & LCM & LRM & TCM & TRM \\
\hline LCM & 0.01 & & & & \\
LRM & 0.06 & 0.72 & & & \\
TCM & 0.01 & 0.51 & 0.74 & 0.69 & 0.48 \\
TRM & 0.07 & 0.66 & 0.03 & 0.22 & 0.00 \\
WFM1 & 0.00 & 0.28 & 0.53 & 0.00 & 0.50 \\
WFM1-5 & 0.00 & 0.36 & 0.00 & \\
\hline
\end{tabular}

${ }^{1}$ Breeding values were predicted from the following model: linear multi-trait model (LMM); linear cross-sectional model (LCM); linear repeatability model (LRM); threshold cross-sectional model (TCM); threshold repeatability model (TRM); Weibull frailty model using data from first lactation (WFM1); and Weibull frailty model using data up to fifth lactation (WFM1-5). 
those obtained from the WFM1-5. This may be because LRM, TRM, and WFM1-5 assume a genetic correlation of unity between survival in the different lactations, although the results from the LMM as well as earlier studies indicate that survival in the first lactation is a distinct trait compared with survival in later lactations; for example, Boettcher et al. (1999) and Sewalem et al. (2007) estimated genetic correlations ranging from 0.78 to 0.85 between survival in first and later lactations.

Many studies of longevity analyze functional herd life (e.g., Chirinios et al., 2007). Functional herd life is the herd life of a cow adjusted for the individual milk production relative to the production level of the herd. This trait definition is used to obtain EBV for survival due to functional traits rather than production. However, individual milk production is likely to be genetically and phenotypically correlated with some functional traits (e.g., mastitis). Furthermore, individual milk production would be least accurately estimated for cows with the shortest lifespans (i.e., cows culled in the early first lactation), which are also more likely to have problems associated with functional traits. Therefore, herd life uncorrected for production was used in the current study.

For prediction of EBV the aim is to select the model that most accurately predicts the performance of future offspring of a bull, and not necessarily the model that gives highest fit of the current data set. Hence, in this study, models were compared with respect to their ability to predict average survival $365 \mathrm{~d}$ after first calving for the second-crop daughters, which depends solely on the quality of the predicted sire evaluations of the 375 elite sires (having at least 1,000 second-crop daughters). The high number of second-crop daughters per sire secures accurate estimation of the performance of second-crop daughters. However, the elite sires are a selected group of sires that is known to reduce the genetic (co)variances within the selected group (Cunningham, 1975). Nevertheless, this effect is expected to be limited, as sires of the Norwegian Red breed are selected on a broad breeding goal not including any direct selection for longevity.

All the models tested in this study were sire models. A full animal model is not possible for some of the software used in these analyses (Survival Kit), or may imply biased estimation of (co)variance in other models (threshold models). In general, use of sire models has the disadvantage that the genetic makeup of the mating partners of the bulls is not taken into account, potentially causing biased EBV in the case of assortative or disassortative mating. However, prediction of sire EBV in this study is based on data from first-crop daughters only (daughters produced for progeny testing). Hence, little was known about the EBV of the bulls before mating, and deliberate selection of mates (except avoiding close relatives) is therefore expected to be of limited importance.

\section{CONCLUSIONS}

When selecting for survival $365 \mathrm{~d}$ after first calving, a linear multi-trait model analyzing survival in the first 3 lactations as correlated traits gave more-accurate sire evaluations than linear, threshold, and Weibull frailty models using data from the first lactation only. Even when the latter models were extended to include data up to sixth lactation, the linear multi-trait model performed somewhat better. Even when including data up to sixth lactation, the Weibull frailty model did not improve predictive ability of sire evaluations over what can be obtained using a simple cross-sectional linear model for binary survival in first lactation.

\section{ACKNOWLEDGMENTS}

Access to the data was granted in agreement number 005.2006 by the Norwegian Dairy Herd Recording System and the Norwegian Cattle Health Service (Ås, Norway). This study is a part of the project "Selection for reduced risk of early culling in dairy cattle: Comparison of alternative approaches to improve animal welfare" (project no. 173276/I10), financed by the Research Council of Norway (Oslo, Norway). H. Yazdi at the Norwegian University of Life Sciences is acknowledged for software assistance.

\section{REFERENCES}

Boettcher, P. J., L. K. Jairath, and J. C. M. Dekkers. 1999. Comparison of methods for genetic evaluation of sires for survival of their daughters in the first three lactations. J. Dairy Sci. 82:10341044 .

Caraviello, D. Z., K. A. Weigel, and D. Gianola. 2004. Comparison between a Weibull proportional hazard model and a linear model for predicting the genetic merit of US Jersey sires for daughter longevity. J. Dairy Sci. 87:1469-1476.

Chirinios, Z., M. J. Carabaño, and D. Hernández. 2007. Genetic evaluation of length of productive life in the Spanish HolsteinFriesian population. Model validation and genetic parameters estimation. Livest. Sci. 106:120-131.

Cunningham, E. P. 1975. Multistage index selection. Theor. Appl. Genet. 46:55-61.

Ducrocq, V., and J. Sölkner. 2000. The Survival Kit V3.12 user's manual. http://www.nas.boku.ac.at/1897.html Accessed November 2007.

Dunn, O. J., and V. Clark. 1971. Comparison of tests of equality of dependent correlation coefficients. J. Am. Stat. Assoc. 66:904908 .

Haile-Mariam, M., P. J. Bowman, and M. E. Goddard. 2003. Genetic and environmental relationships among calving interval, survival, persistency of milk yield and somatic cell count in dairy cattle. Livest. Prod. Sci. 80:189-200.

Holtsmark, M., B. Heringstad, P. Madsen, and J. Ødegård. 2008. Genetic relationship between culling, milk production, fertility, 
and health traits in Norwegian Red cows. J. Dairy Sci. 91:40064012.

Interbull. 2009a. Description of National Genetic Evaluation Systems for dairy cattle traits as applied in different Interbull member countries. http://www-interbull.slu.se/national_ges_info2/ framesida-ges.htm Accessed February 2009.

Interbull. 2009b. Information on national evaluations providing data to the Interbull routine evalutation for direct longevity, as provided by participating countries. http://www-interbull.slu.se/longevity/ l-table3-092.html Accessed August 2009.

Jairath, L., and J. C. M. Dekkers. 1994. Genetic parameters of functional and true lactation survival, and relationships with milk production and conformation traits in registered Canadian Holsteins. J. Dairy Sci. 77(Suppl. 1):146. (Abstr.)

Jamrozik, J., J. Fatehi, and L. R. Schaeffer. 2008. Comparison of models for genetic evaluation of survival traits in dairy cattle: A simulation study. J. Anim. Breed. Genet. 125:75-83.

Jensen, J., and P. Madsen. 2005. Calculation of errors of estimates of genetic and phenotypic parameters in DMU. Danish Institute of Agricultural Sciences (DIAS). Department of Animal Breeding and Genetics. Research Centre Foulum, Tjele, Denmark.
Madsen, P., and J. Jensen. 2008. A User's Guide to DMU. A package for analyzing multivariate mixed models. Version 6, release 4.7. University of Aarhus, Faculty Agricultural Sciences (DJF), Department of Genetics and Biotechnology, Research Centre Foulum, Tjele, Denmark.

Ødegård, J., G. Klemetsdal, and B. Heringstad. 2003. Genetic improvement of mastitis resistance: Validation of somatic cell score and clinical mastitis as selection criteria. J. Dairy Sci. 86:41294136.

Sewalem, A., F. Miglior, G. J. Kistemaker, P. Sullivan, G. Huapaya, and B. J. Van Doormaal. 2007. Short communication: Modification of genetic evaluation of herd.life from a three-trait to a five-trait model in Canadian dairy cattle. J. Dairy Sci. 90:2025-2028.

van Arendonk, J. A. M. 1985. Studies on the replacement policies in dairy cattle. II. Optimum policy and influence of change in production and price. Livest. Prod. Sci. 13:101-121.

Yazdi, M. H., P. M. Visscher, V. Ducrocq, and R. Thompson. 2002. Heritability, reliability of genetic evaluations and responses to selection in proportional hazard models. J. Dairy Sci. 85:15631577 . 